\title{
HISTÓRIA E MEMÓRIA DO INSTITUTO DE EDUCAÇÃO DE PERNAMBUCO
}

\author{
HISTORY AND MEMORY OF THE INSTITUTO DE EDUCAÇÃO DE \\ PERNAMBUCO
}

\section{HISTORIA Y MEMORIA DEL INSTITUTO DE EDUCACIÓN DE PERNAMBUCO}

José Luis Simões ${ }^{1}$

Ana Paula Rodrigues Figueirôa²

${ }^{1}$ Doutor em Educação pela UNIMEP. Docente do Programa de Pós-Graduação em Educação da Universidade Federal de Pernambuco (UFPE), Recife, PE, Brasil.

2Doutora em Educação pela UFPE. Docente do Curso de Educação da Associação Caruaruense de Ensino Superior (ASCES), Caruaru, PE, Brasil.

Resumo: O trabalho discute a transição da Escola Normal Oficial de Pernambuco para o Instituto de Educação de Pernambuco, hoje denominada Escola Sylvio Rabello. A pesquisa representa contribuição para a história das instituições de ensino do Recife, sobretudo para preservação da memória histórica de uma instituição escolar responsável pela formação de mestres das primeiras letras no século XX. A escola, como toda instituição social, sempre foi objeto de inúmeras pesquisas. Desde sua origem até os dias atuais busca-se conhecer a importância de tal instituição para a sociedade, uma vez que influencia na formação dos indivíduos. O objetivo é estudar a história da Escola Normal de Pernambuco até a criação do Instituto de Educação, levando em consideração as práticas pedagógicas, políticas, sociais e as transformações econômicas que consolidaram uma nova sociedade. Observar-se-á que nesse processo também houve a questão da inserção do gênero feminino, e é nessa conjuntura que se volta o olhar para refletir quais foram os motivos que levaram as mulheres a buscar, num ambiente extrafamiliar, uma formação intelectual oposta ao pensamento vigente à época em que, para a mulher, estava reservado o papel de mãe e de dona de casa. A pesquisa tem como referência renomados autores, entre eles: Le Goff e a forma de organização dos documentos; Michel Foucault e a questão do comportamento disciplinador; e Bassanezi, que ajuda a compreender como se dá esse processo de saída da mulher do lar para frequentar a sala de aula. Além das fontes apresentadas, recorrer-se- às ideias consolidadas e construídas por pesquisadores que dedicaram seus estudos à história da educação brasileira. Para responder às interrogações, a metodologia utiliza busca no arquivo do Instituto de Educação de Pernambuco-IEP, no arquivo público estadual e na Fundação Joaquim Nabuco-FUNDAJ. Ademais, a metodologia adotada envolve referências bibliográficas, relatos pessoais (entrevistas com normalistas), utilização de documentários, jornais da época; além da análise iconográfica, que possibilita o conhecimento dos valores, dos costumes, das opiniões, as relações sociais e familiares vivenciadas pelas informantes.

Palavras-chave: Educação; História; Instituição de ensino.

Abstract: The paper discusses the transition from the Escola Normal Oficial de Pernambuco (Official Normal School of Pernambuco) to the Instituto de Educação de Pernambuco (Pernambuco Institute of Education), now called the Sylvio Rabello School. The research represents a contribution to the history of educational institutions in Recife, aiming to preserve the historical memory of a school institution that was responsible for training Masters of the first Letters degrees of the Twentieth 
century. The school, like any other social institution, has been the subject of countless studies. From its origin to the present day, researchers have investigated the importance of this institution to society, as it influences the training of individuals. Our objective is to study the history of the Escola Normal de Pernambuco up until the creation of the Instituto de Educação, taking into account the pedagogical, political, social and economic transformations that consolidated a new society. It is observed that in this process, there was also the question of the insertion of women, and it is at this juncture that we turn our gaze to reflect on what motivated women to look for intellectual training outside the home, at a time when women were expected only to become mothers and housewives. The research uses renowned authors for theoretical background, including: Le Goff on the form of organization of the documents; Michel Foucault on the question of disciplinary behavior; And Bassanezi, who helps us understand this process of women leaving the home to attend educational institutions. In addition to the sources presented, we also use ideas consolidated and built upon by researchers who have dedicated their studies to the history of Brazilian education. To answer the questions, the methodology involves a search in the archives of thee Pernambuco-IEP Institute of Education, the state public archive, and the Joaquim Nabuco-FUNDAJ Foundation. The adopted methodology also involves bibliographical references, personal reports (interviews with adherents of normalism), use of documentaries, newspapers of the time; and iconographic analysis, that gave a better understanding of the values, customs, opinions, and social and family relations experienced by the informants.

Keywords: Education; History; Educational institution.

Resumen: El trabajo discute la transición de la Escuela Normal Oficial de Pernambuco al Instituto de Educación de Pernambuco, hoy denominada Escuela Sylvio Rabello. La investigación representa una contribución a la historia de las instituciones de enseñanza de Recife, sobre todo para preservar la memoria histórica de una institución escolar responsable por la formación de maestros de las primeras letras en el siglo XX. La escuela, como toda institución social, siempre ha sido objeto de innumerables investigaciones. Desde su origen hasta los días actuales se busca conocer la importancia de tal institución para la sociedad, una vez que influye en la formación de los individuos. Nuestro objetivo es estudiar la historia de la Escuela Normal de Pernambuco hasta la creación del Instituto de Educación, teniendo en cuenta las prácticas pedagógicas, políticas, sociales y las transformaciones económicas que consolidaron una nueva sociedad. Se observa que en este proceso también tuvo lugar la cuestión de la inserción del género femenino, y es en esa coyuntura que volvemos la mirada para reflexionar cuáles fueron los motivos que llevaron a las mujeres a buscar, en un ambiente extra familiar, una formación intelectual, opuesta al pensamiento vigente en la época en que, para la mujer, estaba reservado el papel de madre y de ama de casa. La investigación tiene como referencia renombrados autores, entre ellos: Le Goff y la forma de organización de los documentos; Michel Foucault y la cuestión del comportamiento disciplinador; Y Bassanezi, que ayuda a comprender cómo se da este proceso de salida de la mujer del hogar para presenciar el aula. Además de las fuentes presentadas vamos a recurrir a ideas consolidadas y construidas por investigadores que dedicaron sus estudios a la historia de la educación brasileña. Para responder a las interrogantes, la metodología utiliza búsqueda en el archivo del Instituto de Educación de Pernambuco-IEP, en el archivo público estadual y en la Fundación Joaquim Nabuco-FUNDAJ. Además, la metodología adoptada involucra referencias bibliográficas, relatos personales (entrevistas con normalistas), utilización de documentales, diarios de la época; además del análisis iconográfico, que posibilita el conocimiento de los valores, de las costumbres, de las opiniones, las relaciones sociales y familiares vivenciadas por las informantes.

Palabras clave: Educación; Historia; Institución de enseñanza. 


\section{O Tema da Pesquisa}

Percebemos um território extenso, todavia pouco explorado, sobre o estudo da história do Instituto de Educação de Pernambuco (IEP). Então, por motivos de compactação do campo de trabalho, decidimos restringir esta investigação a esta instituição, o que delimita o foco de análise e a investigação, todavia não deixa de ser um grande desafio.

O objetivo deste artigo é analisar a história da Escola Normal de Pernambuco até sua transição para Instituto de Educação de Pernambuco. Dividimos o trabalho em três momentos que se complementam. No primeiro, a particularidade política da época da criação da referida instituição. O segundo momento mostra o caminho percorrido e as diversas denominações da instituição. Por fim, a terceira etapa trata do processo de ingresso com o teste de admissão. Vamos apresentar a transição da Escola Normal Oficial de Pernambuco para Instituto de Educação de Pernambuco, que compreende a primeira década da instituição.

Investigamos o período de 1946 a 1956, marcado pelo discurso que apregoava a formação e a qualificação dos profissionais do ensino, contudo foi um período de ebulição política, pois o Brasil dessa época teve quatro presidentes da república: Eurico Gaspar Dutra (1946 a 1951), Getúlio Dorneles Vargas (1951 a 1954), João Café Filho (1954 a 1955) e Juscelino Kubitschek de Oliveira (1956 a 1961).

Mas ressaltamos que este estudo não é mera revisão bibliográfica. A busca e a organização documental foram fundamentais e, ao mesmo tempo, fascinantes, porque tivemos a sensação de trilhar novos caminhos, de obter documentos históricos, valiosos para a consecução desta pesquisa.

O documento não é inócuo. É antes de mais nada o resultado de uma montagem, consciente ou inconsciente, da história, da época, da sociedade que o produziram, mas também das épocas sucessivas durante as quais continuou a viver, talvez esquecido, durante as quais continuou a ser manipulado, ainda que pelo silêncio. (LE GOFF, 2003, p.537).

E é nesse contexto, segundo Le Goff (2003), que devemos tratar os documentos, pois muitos deles tratam da forma que o seu "instituidor" tem de mascarar, maquiar, algo que se pretende esconder, cabendo ao pesquisador a sua análise e neutralidade. Por conseguinte, é preciso relutância, tempo e determinados equipamentos ao procurar os documentos, selecionando as fontes a serem usadas na pesquisa, considerando a riqueza e a credibilidade que caracterizam o trabalho, e demandam refinamento no tratamento e na compreensão.

Como destacou Le Goff (2003, p. 538), "[...]o documento é uma coisa que fica, que dura, e o testemunho, o ensinamento (para evocar a etimologia) que ele traz devem ser em primeiro lugar analisados desmistificando-lhe o seu significado aparente".

\section{A Particularidade Política}

A ideia de refletir o regime do Estado Novo como processo político da época se dá pelo fato de que o objeto de estudo aparece no fim do Governo de Getúlio Vargas, tendo sofrido 
essas influências, mas não pretendemos exaurir sobre esse período de regência. Vamos focar nos efeitos que a educação perpassou.

Sabemos que a educação está intrinsecamente ligada às relações de poder e que os atos tomados por Gustavo Capanema, então Ministro da Educação e Saúde (1934-1945), tiveram relevância no sistema educacional. Apesar de haver rompimentos com os "intelectuais educacionais" do período, Capanema também tirou a educação da extenuação das épocas anteriores.

Todavia, para o setor educacional, a postura de Capanema já não foi à mesma, pois deixou de lado, praticamente, toda aquela plêiade de jovens educadores (Anísio Teixeira, Fernando de Azevedo, Almeida Junior...), forjados durante o movimento de renovação pedagógica de inspiração escola novista. (CUNHA, 1989, p.18).

No decorrer da primeira década da criação do Instituto de Educação de Pernambuco, houve diversos Ministros da Educação, pois foi um período de transformações políticas. $\mathrm{Na}$ sucessão de Capanema, ao final do Estado Novo, o ministro do então Ministério da Educação e Saúde Pública no Governo interino de José Linhares foi Raul Leitão da Cunha. Houve diversas denominações para os ministérios da educação.

No ministério de Raul Cunha foi baixado o Decreto 8.530, de 02 de janeiro de 1946, que regulamentava o Ensino Normal, conhecido também como Lei Orgânica do Ensino Normal. Para Haidar (2004, p.60), "As leis Orgânicas do ensino normal, primário e agrícola, mesmo projetadas na administração de Capanema e, portanto, sob idêntica inspiração das demais, só saíram em 1946, após a ditadura Vargas". Entretanto, Tanuri (1969) entende que a lei orgânica do Ensino Normal significou o único instrumento do poder central de legislar sobre a organização deste ramo de ensino para todo o território nacional.

A Lei Orgânica do Ensino Normal não introduziu grandes inovações, apenas acabando por consagrar um padrão de ensino normal que já vinha sendo adotado em vários estados. Em simetria com as demais modalidades de ensino de segundo grau, o Normal foi dividido em dois ciclos: o primeiro fornecia o curso de formação de "regentes" do ensino primário, em quatro anos, e funcionaria em Escolas Normais Regionais. (TANURI, 2000, p.15).

Figura 1 - Histórico escolar do primeiro ciclo do Ensino Normal na década de 1950

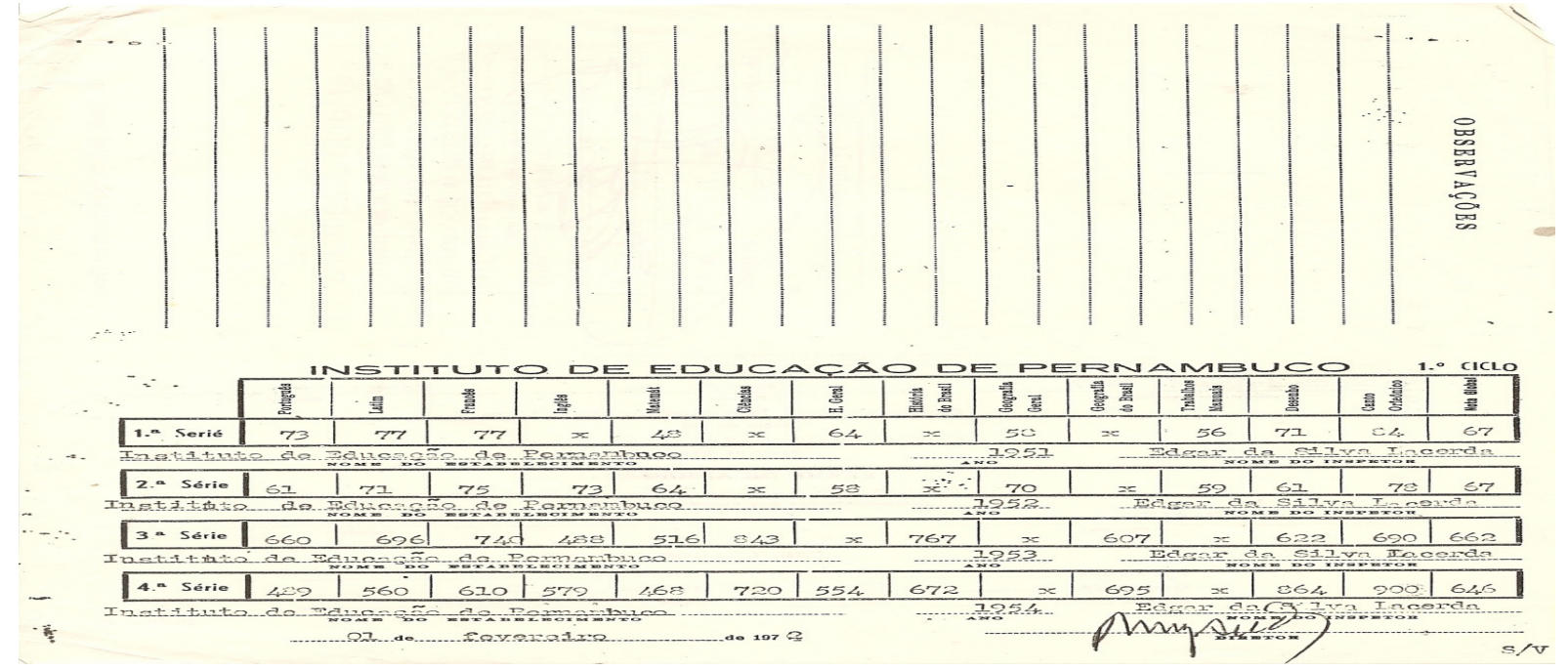

Fonte: Arquivo particular da Normalista Norma Rodrigues. 
O ensino normal foi divido em dois ciclos. No $1^{\circ}$ ciclo, ao concluir os quatro anos de ensino, o aluno tinha o direito à regência do primário. Porém, ao concluir o segundo ciclo, teria a titulação de professor primário. No Instituto de Educação de Pernambuco, o segundo ciclo se dava ao total de três anos, já em outras instituições podiam ocorrer em dois anos, como também diz a lei orgânica, contudo de uma forma mais intensiva.

O curso de segundo ciclo, em dois anos, formaria o professor primário e era ministrado nas Escolas Normais e nos Institutos de Educação. Além dos referidos cursos, os Institutos de Educação deveriam ministrar os cursos de especialização de professores - para a educação especial, curso complementar primário, ensino supletivo, desenho e artes aplicadas, música e canto - bem como cursos de administradores escolares, para habilitar diretores, orientadores e inspetores. (TANURI, 2000, p.16).

Figura 2 - Histórico escolar do segundo ciclo do Ensino Normal na década de 1950

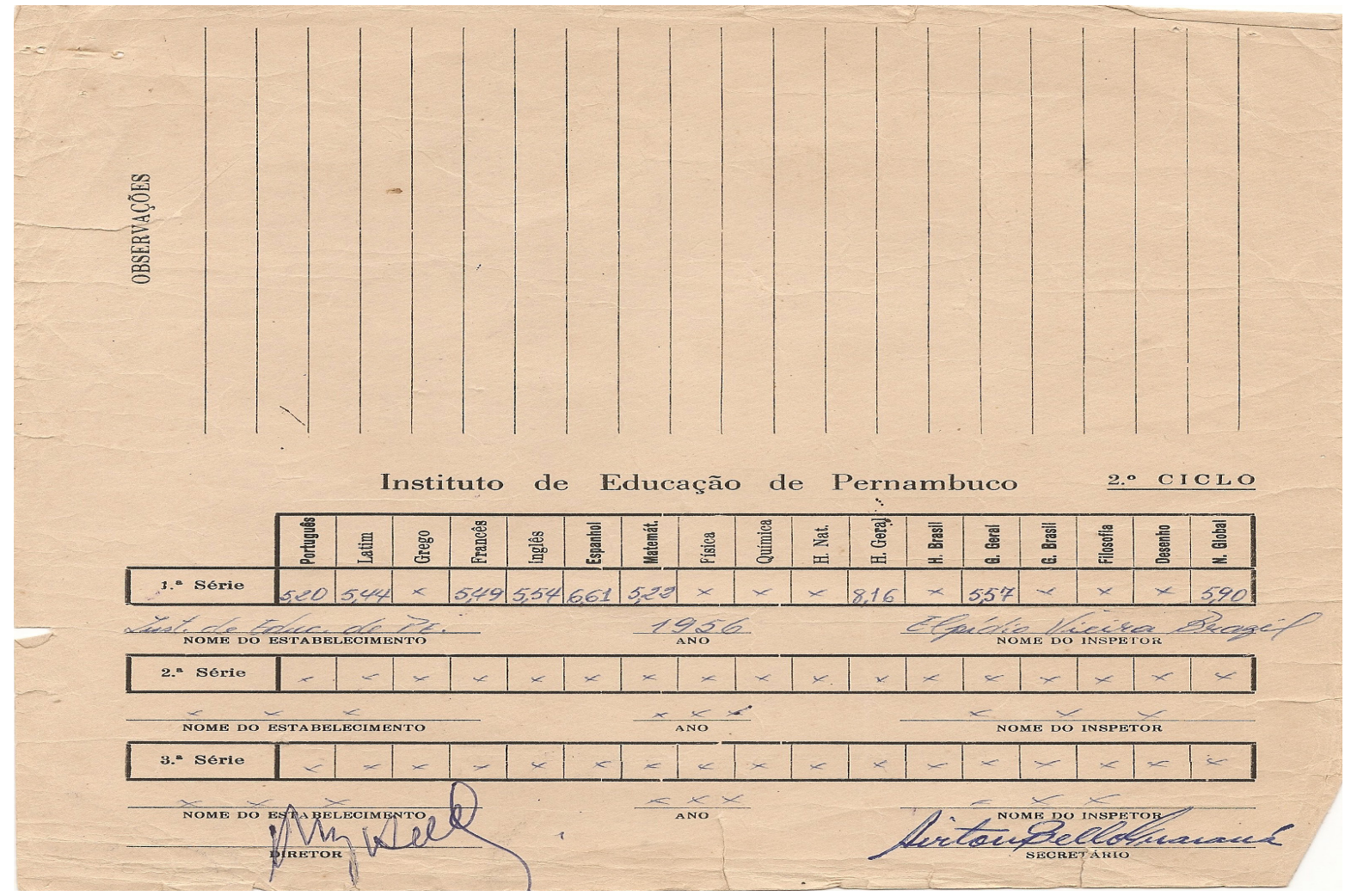

Fonte: Arquivo particular da Normalista Norma Rodrigues.

Esse modelo era centralizador e burocrata, pois uniformizava o ensino normal em todo país, fazendo com que os Estados reformulassem as escolas normais cujas instituições passam a ser institutos educacionais, e cabia aos Estados o direito de adaptar as determinações às diferenças e às necessidades regionais e administrar o ensino, respeitando o espírito da lei.

A política educacional centralizadora traduziu-se na tentativa de regulamentar minuciosamente em âmbito federal a organização e o funcionamento de todos os tipos de ensino no país, mediante "Leis Orgânicas do Ensino", decretos-leis federais promulgados de 1942 a 1946. A Lei Orgânica do Ensino Normal (Decreto-Lei n. 8.530, de 2/1/1946), embora assinada logo após o final da ditadura Vargas, havia sido gestada sob a mesma inspiração anterior, apresentando, entretanto, uma orientação menos centralizadora do que aquela que havia presidido à elaboração dos anteprojetos originais. (TANURI. 2000, p.15). 
A peculiaridade política da época foi o fim do Estado Novo (1945), e os trabalhos de concretização para a Lei da Constituição dos Estados Unidos do Brasil (18 de setembro de 1946), na constituição de 1946, já traziam artigos que "democratizavam" as escolas. Porém, os aprimoramentos na economia e na política tinham intenção de promover um novo projeto social. Nesse contexto, as campanhas para as escolas públicas de qualidade mobilizaram todos os grupos sociais, o que resultou em grande debate e na consolidação da Lei de Diretrizes e Bases da Educação Nacional (1961).

Para Aranha (2006, p.307), "[...] se a lei despertava otimismo, os fatos nem tanto. As inúmeras dificuldades para a sua aplicação se deviam muitas vezes a inadequação à nossa realidade". Ou seja, os Estados não estavam preparados para a ampliação do ensino e da gratuidade, o que determinaria o acesso predominantemente para as elites.

A ebulição política em relação aos poderes é que desencadeia os rumos da educação. Para Haidar (2004), os Estados e o Distrito Federal voltavam a ter a atribuição expressa de organizar os seus respectivos sistemas de ensino. Nesse período, acontece a redemocratização do país e, consequentemente, certo avanço na política educacional.

No Quadro 1, podemos observar a efervescência do ensino normal em todo o Brasil de 1946 a 1956. Estudo realizado pelo Instituto Brasileiro de Geografia e Estatística (IBGE) demonstra o avanço do ensino normal no país, quando em 1946, ano inicial da lei orgânica, havia 382 estabelecimentos que ofereciam o ensino normal, com ampliação no decorrer dos dez primeiros anos para 982 unidades escolares.

Quadro 1 - Desenvolvimento do Ensino Normal no Brasil no Período de 1946 a 1956

\begin{tabular}{|c|c|c|c|c|c|c|}
\hline \multicolumn{7}{|c|}{ O BRASIL EM NÚMEROS } \\
\hline \multicolumn{7}{|c|}{ ENSINO NORMAL DE 1946 A 1959} \\
\hline \multirow{2}{*}{ Anos } & \multirow{2}{*}{$\begin{array}{l}\text { Unidades } \\
\text { escolares }\end{array}$} & \multirow{2}{*}{$\begin{array}{l}\text { Corpo } \\
\text { docente }\end{array}$} & \multicolumn{2}{|c|}{ Matrículas } & \multirow{2}{*}{ Aprovações } & \multirow{2}{*}{$\begin{array}{l}\text { Conclusões } \\
\text { de curso }\end{array}$} \\
\hline & & & Geral & Efetiva & & \\
\hline 1946 & 382 & 3412 & 21597 & 20947 & 20143 & 8077 \\
\hline 1947 & 544 & 4874 & 24958 & 23787 & 21915 & 7383 \\
\hline 1948 & 533 & 4889 & 26014 & 25446 & 24213 & 7692 \\
\hline 1949 & 579 & 5305 & 30457 & 29202 & 27553 & 9902 \\
\hline 1950 & 590 & 5324 & 33436 & 31941 & 30413 & 10114 \\
\hline 1951 & 632 & 5815 & 37824 & 35811 & 33990 & 10777 \\
\hline 1952 & 673 & 6383 & 42473 & 40284 & 38191 & 12994 \\
\hline 1953 & 749 & 7204 & 48724 & 45899 & 42617 & 14829 \\
\hline 1954 & 839 & 8169 & 55206 & 52240 & 48308 & 16235 \\
\hline 1955 & 921 & 9221 & 60286 & 57149 & 52252 & 18164 \\
\hline 1956 & 982 & 9870 & 65096 & 61725 & 56480 & 19364 \\
\hline
\end{tabular}

Fonte: IBGE (2011).

Porém, como podemos pensar em avanços educacionais, ensino gratuito para todos e a redemocratização se no final da década de 1947 ainda havia os interventores escolhidos 
politicamente como "homens de confiança" e subordinados ao Estado Maior? Os interventores estaduais detinham o poder sobre os Estados (Decreto-lei 1202, de 08 de abril de 1939). De acordo com Cunha (1989, p.32), "[...] os governadores são substituídos por interventores, meros executores de ordens vindas de cima". Esse decreto trata sobre a administração dos estados e dos municípios de forma subordinativa, rígida, autoritária e centralizadora.

Havia um órgão mediador para os interventores chamado de Departamento Administrativo do Serviço Público (DASP), que tinha como objetivo a moralização administrativa perante Estados e Municípios, ou seja, todo decreto, todo ato governamental teria que passar pelo crivo do DASP, afinal, ele era um órgão ligado ao governo federal.

Num regime forte, o DASP acabou por transformar-se num super ministério.
Dirigido por tecnocratas, marginalizava a influência política. Interventores e
prefeitos a ele se submetiam. Leis e decretos estaduais, embora fossem da alçada
do interventor, deveriam receber aprovação dos "daspinhos". (CUNHA, 1989, p.32).

Em Pernambuco não foi diferente. Houve intervenção de 1930 a 1947. O general Dermeval Peixoto foi o interventor que acatou a ordem da Lei Orgânica pelo Decreto 8.530, de 02 de janeiro de 1946, que trasladou a Escola Normal para Instituto de Educação de Pernambuco.

A Escola Normal de Pernambuco tinha como objetivo formar professores para atuar no magistério de ensino primário e de nível secundário (hoje Ensino Normal Médio), em que ampliaria e difundiria os conhecimentos relativos à educação infantil, a partir da criação do Instituto de Educação de Pernambuco, pelo Decreto-Lei 1448, de 03 de setembro de 1946.

Figura 3 - Decreto-Lei 1448, de 03 de setembro de 1946

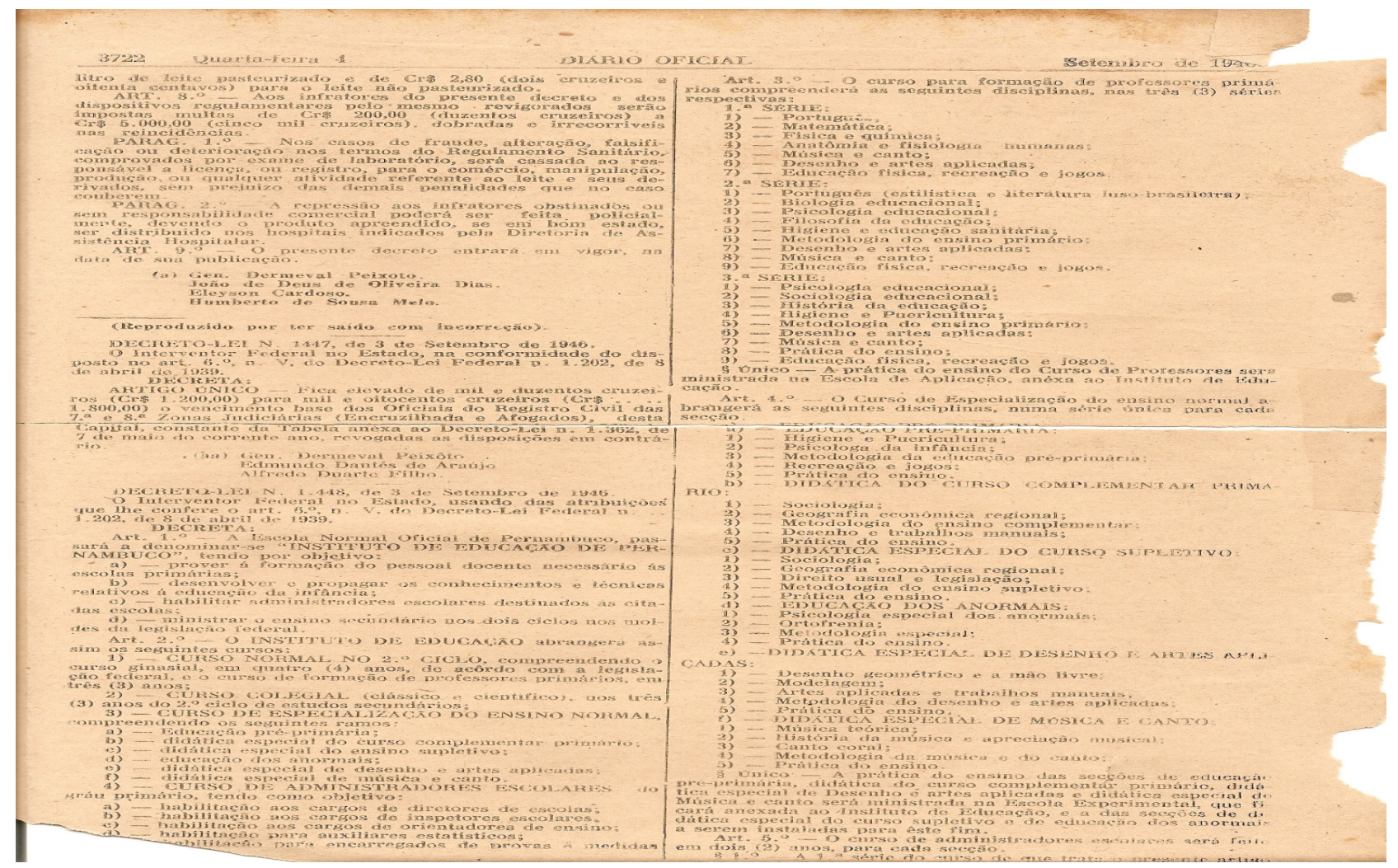

Fonte: Diário Oficial de Pernambuco 04 de setembro de 1946 (Arquivo Público de Pernambuco). 
Pela data da publicação do decreto em Pernambuco, podemos compreender que, após a publicação da Lei Orgânica Federal, Decreto 8530 de 02 de janeiro de 1946, o Estado passou sete meses para a publicação do seu decreto e a criação do Instituto de Educação. Entretanto, essa formulação do Instituto era compacta. Não houve a criação dos outros centros, que tinham uma vinculação maior, ou seja, abrangeria não só o ensino normal como também a educação infantil, o ensino primário, o ensino ginasial e o científico.

\section{O Caminho Percorrido}

A Escola Normal Oficial de Pernambuco foi inaugurada em 1865, mas vale salientar que essa modalidade de estabelecimento já existia em diversas capitais do Brasil. A primeira escola Normal brasileira foi no Estado do Rio de Janeiro. Segundo Romanelli (2005, p.163), " [...] a primeira delas foi criada em 1830, em Niterói, sendo pioneira na América Latina". Passaramse mais de 30 anos para se criar a Escola Normal de Pernambuco, e uma das hipóteses da demora demanda questões políticas.

A Escola Normal de Pernambuco estava situada primeiramente na Torre antiga da Alfândega, no bairro do Recife. Em seguida, passou a realizar suas atividades no casarão colonial à Rua da Praia. Em 1900, sua localização foi nas dependências do Ginásio do Recife, atual Ginásio Pernambucano. Seu primeiro prédio próprio foi em 1920, na Praça Adolfo Cirne, mas, em 1962, começaram as obras para a transferência da Câmara de Vereadores do Recife para o referido local, onde até então funcionava a Escola Normal, situada na Rua Princesa Isabel, ao lado do Parque Treze de Maio, na Boa Vista.

Essas mudanças aconteceram nos governos de Miguel Arraes (governador de Pernambuco) e do Engenheiro Arthur Lima Cavalcanti (prefeito do Recife). Consequentemente, a Escola Normal foi transferida para o atual Instituto de Educação de Pernambuco (IEP), precisamente na Escola Sylvio Rabello, situado entre a Avenida Mario Melo e o Parque 13 de Maio.

Hoje denominada Escola Sylvio Rabello, pertence ao Instituto de Educação de Pernambuco. A Escola recebeu diversos nomes ao longo da sua trajetória. As várias mudanças se explicam pelo fato de que, ao longo do século $X X$, diversas reformas foram implantadas pelo governo no que se refere à educação brasileira.

O Brasil passou por mudanças políticas, econômicas e sociais e a educação também sofreu esse processo. Para Barroso Filho (2008, p.82), "na década de 1950, a economia pernambucana já não ocupava a posição que fizera da província um dos esteios da nação. A economia urbano-industrial oferece um novo suporte para a produção cultural e os arautos do Brasil moderno exigiam uma nova cultura, uma nova educação, uma nova escola". 
Figura 4 - Vista da Câmara dos Vereadores do Recife, antiga Escola Normal Oficial de Pernambuco e o atual Instituto de Educação de Pernambuco

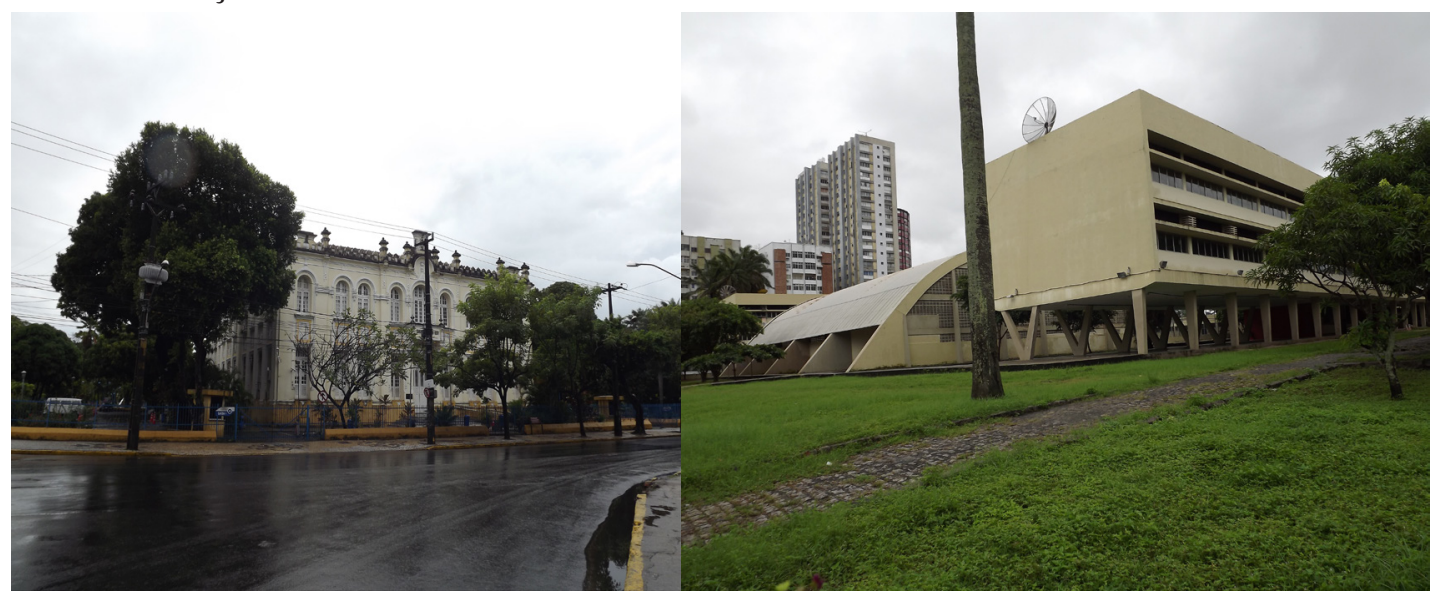

Fonte: A pesquisa (2014).

O Centro Integrado foi composto pelas seguintes escolas: Jardim de Infância Ana Rosa Falcão de Carvalho (Ensino Infantil), Escola Cônego Rochael de Medeiros (Ensino Primário), Escola João Barbalho (Ensino Ginasial), Escola Sizenando Silveira (Ensino Científico) e a Escola Sylvio Rabello (Ensino Profissionalizante). A imagem a seguir é o símbolo do Instituto de Educação de Pernambuco, sendo que as cinco estrelas estão representando as escolas citadas anteriormente.

Figura 5 - Símbolo do Instituto de Educação de Pernambuco

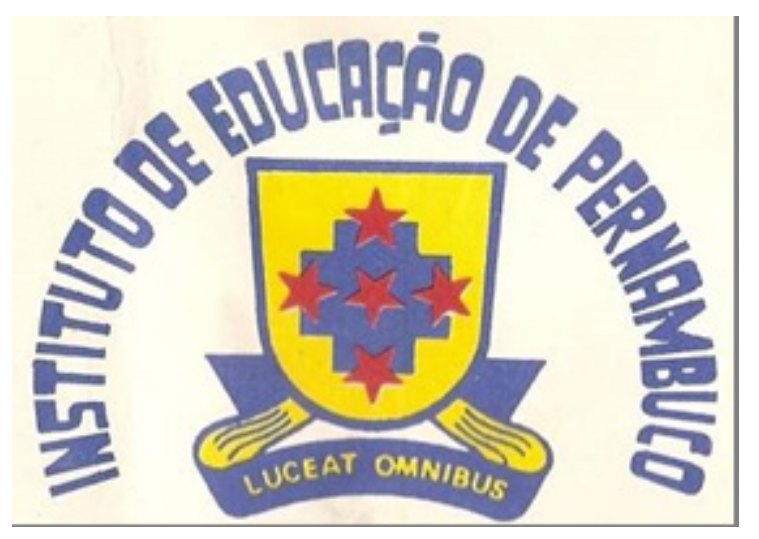

Fonte: Arquivo particular da autora.

Vejamos a análise de Le Goff (1983, p.93), ao interpretar os símbolos utilizados para justificar o poder: "o símbolo é sinal de um contrato. É a referência a uma unidade perdida, recorda e evoca uma realidade superior e oculta".

A tradução da palavra que está no símbolo "Luceat omnibus", segundo o dicionário de sentenças Latinas e Gregas (TOSI, 2000, p.321), significa "que a luz brilhe para todos". Para Le Goff (1983, p.101), "[...] a luz é objeto das mais ardentes aspirações, está carregada dos mais altos símbolos". Esta tradução pode deixar subentendido que a luz do saber e que a 
educação nos diversos níveis seja para todos, ou seja, uma educação descentralizadora, para o povo, em que todos tenham acesso, o que revela influência do Manifesto dos Pioneiros da Educação Nova. Para Aranha (2006), o Manifesto "[...] defendia a educação obrigatória, pública, gratuita e leiga como dever do Estado, a ser implantada em programa de âmbito nacional" (ARANHA, 2006, p.303).

A estruturação como Centro Integrado Instituto de Educação de Pernambuco aconteceu por meio do Decreto Estadual n 2.631, de 26 de outubro de 1972, que se baseou na Lei Federal 5.692, de 11 de agosto de 1971, que trata das Diretrizes e Bases para a Educação Nacional. Mediante o exposto, o governador de Pernambuco, Eraldo Gueiros Leite (1971-1975), decretou a reestruturação do Instituto de Educação de Pernambuco. Porém, vale ressaltar que o Instituto de Educação já existia e foi criado o complexo educacional, agregando outras unidades de ensino. Constituindo, assim, unidades de ensino em torno do Parque Treze de Maio, que beneficiava a população desde o ensino pré-escolar até o ensino de $1^{\circ}$ e $2^{\circ}$ graus, e o profissionalizante se dava no Sylvio Rabello, com cursos de técnico em enfermagem e o magistério.

Essas reformas se deram em várias instâncias, inclusive no fardamento e na estrutura física do prédio, onde, segundo Lima (1985, p.89), houve um concurso de arquitetura em 1956, obra essa de grande importância no cenário local, e que contribuiu na afirmação profissional dos jovens arquitetos: Marcos Domingues e Carlos Correia Lima.

Porém, esses jovens arquitetos só participaram da elaboração do projeto do IEP, porque o mesmo se deu por meio de concurso, pois na época havia discussões por que não entregar essa obra a arquitetos renomados, como Oscar Niemeyr e Lúcio Costa. Inclusive essa lembrança nominal de arquitetos foi motivo de contendas e publicações na imprensa local. Edison Lima comenta sobre uma publicação da Folha da Manhã do dia 8 de janeiro de 1956, no seu livro: Modulando: notas e comentários sobre arquitetura e urbanismo, retratando a importância desse concurso.

Finalmente está aberto o Concurso de projetos para o novo edifício do
Instituto de Educação de Pernambuco. Como não poderia deixar de ser, a
notícia é realmente de grande importância, não só para o público em geral,
pois assim recrudescem as esperanças de se dar à velha e tradicional Escola
Normal um prédio mais condigno com sua condição de formadora da
juventude pernambucana, mas também, e de modo particular, para nós que
fazemos o Instituto de Arquitetos do Brasil. (LIMA, 1985, p.92).

De acordo com Lima (1985, p.89), “[...] as razões são óbvias, pois se trata de dar à antiga e tradicional Escola Normal Oficial de Pernambuco, uma nova sede condigna com seu alto prestígio e que venha atender verdadeiramente às suas reais necessidades" e que seja planejada por arquitetos locais.

Percebemos que a contextualização em torno do IEP é incomensurável, pois se trata de uma instituição de prestígio social, se a sua estrutura física é notória pela grandiosidade e pela localização o seu símbolo também é marcante, também fazendo aludir a memória da população. 


\section{Processo de Ingresso com o Teste de Admissão}

Para ingressar na Escola Normal Oficial de Pernambuco, havia o teste de admissão, com certas restrições legais no processo de ingresso, cuja candidata deveria passar pelo teste, que era bastante rigoroso.

O exame está no centro dos processos que constituem o indivíduo como efeito e objeto de poder, comoefeitoeobjeto de saber.Éeleque, combinandovigilânciahierárquicaesançãonormalizadora, realiza as grandes funções disciplinares de repartição e classificação. (FOUCAULT, 2009, p.183).

Obrigatórios pela lei orgânica do ensino normal no título III do capítulo III, os exames de admissão a esse nível de ensino se configurava uma barreira difícil de ser ultrapassada pela grande massa dos alunos que vinham do ensino primário. "A certeza de que este era um nível de ensino reservado para uma 'elite' pode ser encontrada na seletividade que, na época, equivalia ao dos vestibulares a partir da década de 70" (PESSANHA, 1994, p. 85).

Figura 6 - Teste de admissão de 1951

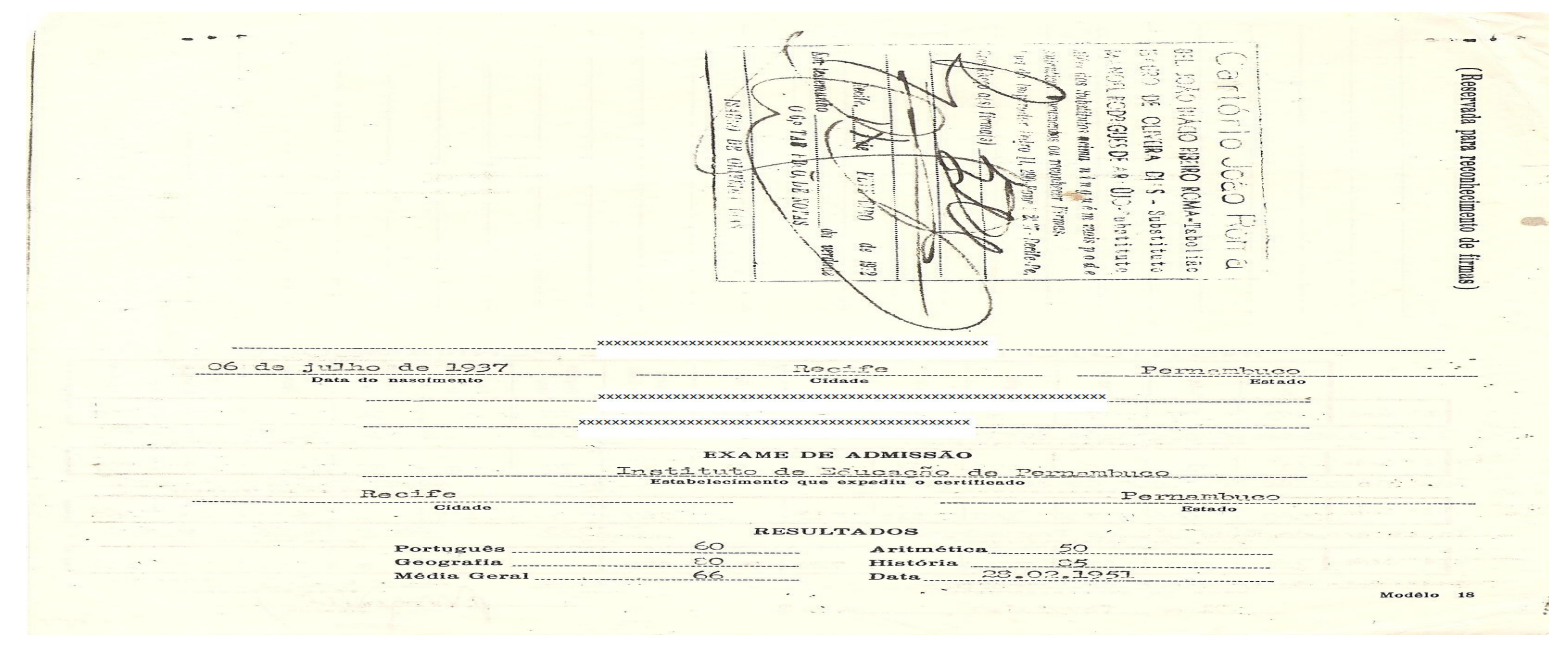

Fonte: Arquivo particular da Normalista Norma Rodrigues.

Esses exames eram elaborados pelas próprias escolas com extrema rigidez e tinham como objetivo qualificar e classificar, como mostra o capítulo da lei federal. Não era necessário só o conhecimento intelectual, mas também idade específica, sanidade física e mental, tendo como viés as questões do higienismo e a normatização que tinham como objetivo os procedimentos legais de preservação da raça sadia e com isso a qualidade racial, a fim de não oferecer problemas à ordem pública (CHALHOUB,1996).

Em Pernambuco, o teste de admissão não foi diferente. O regulamento do ensino normal no capítulo IV, criado na década de 1950, passou a ter os mesmos requisitos de acordo com a lei orgânica. Podemos observar que, de acordo com o regulamento, o teste da imagem anterior demonstrada abrange as disciplinas regulamentadas, porém não demonstra se a submissão foi escrita ou oral; e no lugar de matemática temos aritmética. A estudante obteve a média 66 e também tinha 14 anos, ou seja, foi aprovada, pois para 
obter aprovação, era necessária a média cinco e idade mínima de 15 anos para o segundo ciclo, não obstante das seleções em relação às disciplinas exigidas para o processo seletivo: Português, Aritmética (Matemática), Geografia e História.

Quando buscamos a profissão, é sempre uma tentativa de unir a necessidade imposta pela sociedade com algum nível de prazer. Em geral, esse prazer é associado a uma sensação de dever cumprido com ligação emocional com a profissão, ao reconhecimento dado por outrem da importância/eficácia do seu trabalho ou à compensação financeira.

Mas sabemos que a busca da profissionalização está atrelada a diversos fatores, desde modismos da época, até a própria vocação. Nessa época era status ter a filha no curso normal, pois não só preparava para uma profissão como também para o casamento, ou seja, servia para a organização do lar, os bons costumes e a educação dos filhos.

Considerado o mais próximo da função de "mãe", o magistério era o curso mais procurado pelas moças, o que não significava sequer que todas as estudantes fossem exercer a profissão ao se formarem, pois muitas contentavam-se apenas com o prestígio do diploma e a chamada "cultura geral" adquirida na escola normal. (BASSANEZI, 2008, p.625).

Inicialmente, a Escola Normal era apenas masculina, só depois o acesso foi permitido às mulheres. Apesar das dificuldades, as escolas normais desempenharam um papel de grande importância não só na educação brasileira, mas em vários estados, e um deles foi Pernambuco.

Na província de Pernambuco, em 1836, uma lei estabelece a criação de uma escola normal do ensino mútuo que, entretanto, nunca foi instalada. Apenas em 1864, a Lei 598 de $13 / 5$ determinava que se instituísse uma escola normal do sexo masculino com dois anos de curso, escola esta instalada em 1865. Quatro anos depois, ou seja, em 1869, o curso já seria aumentado para três anos e em 1887 para quatro. (TANURI, 1969, p.17).

É a partir dessa época que começa a democratização do ensino feminino, que teve início com as escolas normais, já que antes eram somente para o sexo masculino e para famílias ricas. Vale ressaltar que já havia escolas confessionais/internatos e religiosas desde o final do século XIX para o sexo feminino, mas com objetivos diferentes. A finalidade da Escola Normal era formar professores para ministrar aulas no antigo ensino primário. A lei geral de 15 de outubro de 1827 estabelecia o que os meninos e as meninas deviam aprender.

Que conhecimentos transmitiriam essa escola elementar prometida pelo governo a todos os cidadãos? Dispunha 0 art. $6^{\circ}$ : Aos meninos os professores ensinarão a ler as quatro operações da Aritmética, prática de quebrados, decimais e proporções, as noções mais gerais da geometria prática, a gramática da língua nacional e os princípios da moral cristã e da doutrina da religião católica e apostólica romana, proporcionados à compreensão dos meninos, preferindo para as leituras a Constituição do império e a História do Brasil. Rezava a lei: Às meninas, as mestras, além do declarado no art.6 $6^{\circ}$, com exclusão das noções de Geometria, e limitando a instrução da Aritmética só às suas quatro operações, ensinarão também as prendas que servem à economia doméstica. (HAIDAR, 2004, p.40).

Esse cenário que tentamos desvendar sobre oIEP teve como finalidade mostrar asociedade, como foi a transposição da Escola Normal Oficial de Pernambuco para o referido instituto, em que ele foi criado por meio do cumprimento das leis, dos decretos e dos regulamentos, trazendo mudanças e, consequentemente, modernização na educação de Pernambuco, proporcionando vagas para as camadas mais populares, pois até então eram prioridade das elites estudar em uma instituição renomada. 


\section{CONSIDERAÇÕES FinAIS}

Desvelar a história de uma instituição educacional é entender o presente, baseado no passado, dentro dos institutos que ofertavam o ensino normal para a formação das primeiras professoras primárias, como também o acesso aos arquivos do Instituto de Educação de Pernambuco, da FUNDAJ, do arquivo público de Pernambuco e aos documentos privativos daquelas professoras, denominadas "normalistas", que guardaram imagens e outros documentos do período escolar.

Foi possível constatar que essas instituições de ensino normal, e especificamente o IEP, se consolidaram por meio das normatizações e dos modelos preestabelecidos pelos decretos e outros tipos de documentos que abriram o leque para a inserção dessa modalidade de ensino e especificamente para as mulheres, pois por vários anos o ensino normal era exclusivamente masculino.

A ampliação do ensino normal se materializou para atender às necessidades do processo de industrialização e urbanização, consequentemente, os homens começaram a deixar o curso normal para participar do processo de industrialização, pois a remuneração seria melhor do que a profissão de professor. Todavia, o horário de trabalho passaria de seis para oito horas diárias para os homens, e a mulher (normalistas) trabalharia um turno, restando o tempo para a educação dos filhos e o cuidado com o lar.

Portanto, considera-se que os processos educacionais e sociais são um conjunto de significações que foi sendo instaurado ao longo da história desta instituição, não só no processo de formação dos professores, como também na coletividade social. A transição social para o processo de urbanização e modernização refletiu no sistema educacional dentro do contexto histórico .

Outro aspecto que demonstramos nessa pesquisa foram as disciplinas ofertadas no primeiro e segundo ciclos. Percebemos que no primeiro ciclo, além das disciplinas consideradas básicas, havia as disciplinas voltadas para o ensino normal, como Trabalho manual; e as mais específicas, como Canto orfeônico. Estabelecia-se, assim, "bom-mocismo", ou seja, as mulheres estavam voltadas para uma sistematização plena de educação, mas fica a indagação se havia essa intencionalidade de uma educação pautada nos bons costumes, porque o ensino religioso não consta nas duas matrizes apresentadas nas figuras 1 e 2 .

Mas no segundo ciclo as disciplinas que convergem com o primeiro foram mais específicas para os possíveis processos seletivos como concursos e vestibular, como: Física e Química, dentre outras: Grego, Espanhol, História Natural e Filosofia.

A instauração do Instituto de Educação de Pernambuco, que em outrora era denominado de Escola Normal oficial de Pernambuco, perpassou pelas demandas legais em nível nacional e estadual, pela organização administrativa e pedagógica, como também um concurso para a planta de sua nova sede, acontecimento que para a época não era tão comum, principalmente no período da ditadura, ressaltando que todo esses contexto era pautado na formação dos futuros professores. 
Portanto, falar da história e da memória de uma instituição formadora de professores é realçar um formato de educação visto pelos documentos de forma normativa e centralizadora, disciplinadora e de excelência no ensino, que ultrapassando os muros escolares e entrelaçando a sociedade.

\section{REFERÊNCIAS}

ARANHA, M. L. de A. História da educação da pedagogia: geral e Brasil. 3.ed., rev. e ampliada. São Paulo: Moderna, 2006. 384 p.

BARROSO FILHO, G. Memórias escolares do Recife: o ginásio pernambucano nos anos de 1950. Recife: Livro Rápido, 2008. 246 p.

BASSANEZI, C. Mulheres dos anos dourados. In: PRIORE, M. D. História das mulheres no Brasil. 9 ed. São Paulo: UNESP, 2008. 678 p.

BRASIL. Anuário do Brasil 1960. Serviço de Estatística da Educação e cultura. RJ, 1960. Disponível em: <http://www.ibge.gov.br/seculoxx/arquivos_xls/palavra_chave/educacao/ensino_normal.shtm> Acesso em 01 de fevereiro de 2011.

BRASIL. Constituição dos estados unidos do Brasil de 18 de setembro de 1946. Brasília, DF, 1946. Disponível em: <http://www.planalto.gov.br/ccivil_03/constituicao/Constitui\%C3\%A7ao46.htm>. Acesso em 30 de novembro de 2010.

BRASIL. Decreto-Lei n.8.530 de 2 de janeiro de 1946. A Lei Orgânica do Ensino Normal. Brasília, DF, 1946. Disponível em: http://www.senado.gov.br>. Último acesso em 11 de novembro de 2006.

BRASIL. Decreto-lei no $1202 \backslash$ 08.04.1939. Administração dos Estados e dos Municípios. Brasília, DF, 1939. Disponível em: http://www2.camara.gov.br/legin/fed/declei/1930-1939/decreto-lei-12028-abril-1939-349366-publicacao-1-pe.html. Acessado em: 02/01/2011.

BRASIL. Lei 4.024, de 20 de dezembro de 1961. Fixa as Diretrizes e Bases da Educação Nacional. Brasília: DF, 1961. Disponível em:< http://www6.senado.gov.br/legislacao/ListaTextoIntegral. action?id=75529.htm> . Acesso em: 25 jan. 2017.

BRASIL. Lei No 5.692, de 11 de agosto de 1971. Brasília, DF, 1971. Disponível em: <http://www. planalto.gov.br/ccivil_03/Leis/L5692.htm>. Acesso em 23 de outubro de 2010.

CHALHOUB, S. Cidade febril: Cortiços e epidemias na corte imperial. São Paulo: Companhia das letras, 1996.

CUNHA, C. da. Educação e Autoritarismo no Estado Novo. Cortez: Autores Associados. São Paulo, SP. 1989.

FOUCAULT, M. Vigiar e punir: nascimento da prisão; tradução de Raquel Ramalhete. 37. ed. Petrópolis, RJ: Vozes, 2009. 291 p.

HAIDAR, M. de L. M. A evolução da educação básica no Brasil: Política e Organização. In: MENESESM J. G. C. (Org.) Educação Básica: Políticas, legislação e Gestão - Leituras. São Paulo: Thomson, 2004. pp. 36-67.

LE GOFF, J. A civilização do ocidente medieval. Lisboa: Estampa, 1983. 384 p. v. 2.

LE GOFF, J.; FERREIRA, I.; LEITÃO, B.; BORGES, S. F. (Trad.). História e memória. 5. ed. Campinas, SP: Ed. UNICAMP, 2003. 541 p. 
LIMA, E. R. de. Modulando: notas e comentários: arquitetura e urbanismo. Recife: Fundação de Cultura Cidade do Recife, 1985. 183 p.

PESSANHA, E. C. Ascensão e queda do professor. São Paulo: Cortez, 1994. 112p.

RECIFE. http://www.camara.recife.pe.gov.br/institucional. Acesso em 23 de outubro de 2010.

ROMANELLI, O. de O. História da educação no Brasil, (1930 / 1973). 29. ed. Petrópolis, RJ: Vozes, 2005. $267 \mathrm{p}$.

TANURI, L. M. Contribuição para o estudo da escola normal no Brasil. 1969. Dissertação (Mestrado)

- Faculdade de Educação da Universidade de São Paulo, São Paulo, 1969.

TANURI, L. M. "História da formação de professores". Revista Brasileira de Educação, n. 14, mai/jun/ jul/ago de 2000 (Número Especial - 500 anos de educação escolar), 2000. p. 61-88.

TOSI, R. Dicionário de sentenças latinas e gregas: 10.000 citações da antiguidade ao renascimento no original e traduzida com comentário histórico, literário e filológico. 2.ed. São Paulo: Martins Fontes, 2000. 904 p.

Artigo recebido em: 26/02/2018

Aprovado em: 14/06/2018

Contato para correspondência:

José Luis Simões.

E-mail: joseluis2711@yahoo.com.br 